\title{
Graves’ Disease: Can It Be Cured?
}

\author{
Wilmar M. Wiersinga \\ Department of Endocrinology and Metabolism, Academic Medical Center, University of Amsterdam, Amsterdam, \\ The Netherlands
}

Whether or not Graves' hyperthyroidism can be really cured, depends on the definition of "cure." If eradication of thyroid hormone excess suffices for the label "cure," then all patients can be cured because total thyroidectomy or high doses of ${ }^{131}$ I will abolish hyperthyroidism albeit at the expense of creating another disease (hypothyroidism) requiring lifelong medication with levothyroxine. I would not call this a "cure," which I would like to define as a state with stable thyroid stimulating hormone (TSH), free thyroxine, and triiodothyronine serum concentrations in the normal range in the absence of any thyroid medication. Surgery and radioiodine are unlikely to result in so-defined cures, as their preferable aim as stated in guidelines is to cause permanent hypothyroidism. Discontinuation of antithyroid drugs is followed by $50 \%$ recurrences within 4 years; before starting therapy the risk of recurrences can be estimated with the Graves' Recurrent Events After Therapy (GREAT) score. At 20 -year follow-up about $62 \%$ had developed recurrent hyperthyroidism, $8 \%$ had subclinical hypothyroidism, and 3\% overt hypothyroidism related to TSH receptor blocking antibodies and thyroid peroxidase antibodies. Only $27 \%$ was in remission, and might be considered cured. If the definition of "cure" would also include the disappearance of thyroid antibodies in serum, the proportion of cured patients would become even lower.

Keywords: Graves hyperthyroidism; Cure; Thyroidectomy; Radioactive iodine; Antithyroid agents; Remission; Long term outcome

\section{INTRODUCTION}

Graves' disease, can it be cured? A most relevant question for patients diagnosed with Graves' hyperthyroidism, which occurs in a substantial number of subjects as the prevalence in the general population is in the order of $1 \%$ to $1.5 \%$ [1]. The incidence is 20 to 30 cases per year per 100,000 persons [2,3].

Approximately $3 \%$ of women and $0.5 \%$ of men develop Graves' disease during their lifetime [2]. Graves' hyperthyroidism is the most common phenotype of Graves' disease; the other phenotypes Graves' orbitopathy (GO) and Graves' dermopathy (local myedema) are relatively rare and not taken into consider-

Received: 19 February 2019, Revised: 28 February 2019,

Accepted: 5 March 2019

Corresponding author: Wilmar M. Wiersinga

Department of Endocrinology and Metabolism, Academic Medical Center, University of Amsterdam, Room F5-169, Meibergdreef 9, Amsterdam 1105AZ, The Netherlands

Tel: +31-20-5666071, Fax: +31-20-6183468, E-mail: w.m.wiersinga@amc.uva.nl ation in the following discussion on cure.

The natural history of Graves' hyperthyroidism is not well known. The main reason for this deficiency in our knowledge is that nowadays all patients with Graves' hyperthyroidism are treated in order to restore euthyroidism. Effective therapy with antithyroid drugs (ATDs) or radioactive iodine (RAI) has been available since the end of the Second World War, but even in the first half of the twentieth century patients could be successfully treated with thyroidectomy $\left(\mathrm{T}_{\mathrm{x}}\right)$. Based on the older literature, attempts have been made to describe the natural history of Graves' hyperthyroidism [4]. Most patients (estimated $60 \%$ to $70 \%$ ) follow an undulating course with alternating hyperthyroid

\footnotetext{
Copyright () 2019 Korean Endocrine Society

This is an Open Access article distributed under the terms of the Creative Commons Attribution Non-Commercial License (http://creativecommons.org/ licenses/by-nc/4.0/) which permits unrestricted non-commercial use, distribution, and reproduction in any medium, provided the original work is properly cited.
} 


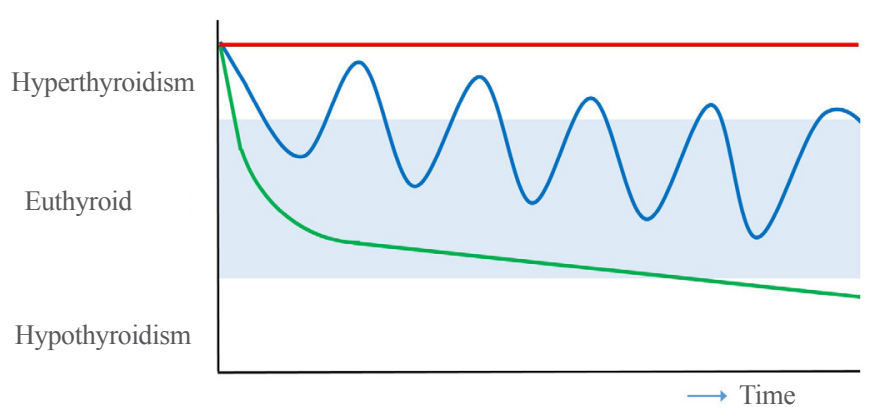

Fig. 1. Hypothetical curves reflecting the natural history of Graves' hyperthyroidism. A minority of patients (green line) have a single episode of hyperthyroidism. The majority (blue line) has a prolonged course following a relapsing and remitting course over many years. In some patients (red line) the disease never remits but continues to express herself clinically. In the long-term the natural course along the green and blue curves could evolve towards spontaneous development of hypothyroidism.

and euthyroid episodes (Fig. 1, blue line). A minority (about $30 \%$ to $40 \%$ ) experiences just one hyperthyroid episode (Fig. 1, green line). In some patients (not more than $10 \%$ ) hyperthyroidism never remits and it is thought that in this group with perpetual hyperthyroidism the disease can be fatal if left untreated (Fig. 1, red line).

We can influence the course of Graves' hyperthyroidism by $T_{x}, R A I$, or ATD. Do these interventions really change the natural course of Graves' hyperthyroidism? Is the disease cured after a successful intervention?

\section{THYROIDECTOMY}

If surgery is chosen for Graves' hyperthyroidism, current guidelines recommend total thyroidectomy $\left(\mathrm{TT}_{\mathrm{x}}\right)$ as the procedure of choice rather than subtotal thyroidectomy $\left(\mathrm{STT}_{\mathrm{x}}\right)[5,6] . \mathrm{TT}_{\mathrm{x}}$ has a nearly $0 \%$ risk of recurrence, whereas $\mathrm{STT}_{\mathrm{x}}$ may have an $8 \%$ chance of persistence or recurrence of hyperthyroidism at 5 years [7-9]. Serum concentrations of thyroid-stimulating immunoglobulins (TSIs) rapidly decrease during the first 9 months after $\mathrm{TT}_{\mathrm{x}}$ but are still detected in $18 \% 3$ years later [10]. One may conclude that $\mathrm{TT}_{\mathrm{x}}$ is capable to definitively cure the hyperthyroid state, but at the expense of creating another diseasehypothyroidism.

The above does not exclude the possibility to maintain a longterm remission of Graves' hyperthyroidism after $\mathrm{STT}_{\mathrm{x}}$. A recent study enrolled 415 consecutive patients with Graves' hyperthyroidism who underwent bilateral $\operatorname{STT}_{\mathrm{x}}(n=385)$ or the Dunhill procedure (hemithyroidectomy+subtotal resection) $(n=57)$ [11].
Median postoperative follow-up was 6 years. Persistent or recurrent hyperthyroidism occurred in $29 \%$. Thyroid remnant weight was on average $5.1 \mathrm{~g}$, and appeared to be an independent risk factor for persistent or recurrent hyperthyroidism (hazard ratio, 1.32). Hypothyroidism developed in over $50 \%$ of patients. Only $19 \%$ of patients remained euthyroid, and the rate did not increase significantly as thyroid remnant weight increased. This last finding does not support a recommendation done in the past to adjust the remnant size to the thyroid peroxidase or microsomal antibody (TPO-Ab) concentration in order to achieve the greatest likelihood of a postoperative euthyroid state: remnant size should be about $3 \mathrm{~cm}^{3}$ at low TPO-Ab concentrations but around $5 \mathrm{~cm}^{3}$ in case of high TPO-Ab levels [12]. It follows that STT $_{x}$ with the intent to maintain a euthyroid state, is not an optimal surgical strategy because the persistence or recurrence rate of Graves' hyperthyroidism is high and the euthyroid rate is low.

\section{RADIOACTIVE IODINE}

American Thyroid Association (ATA) guidelines stipulate the goal of RAI therapy (like that of surgery) in Graves' disease is to control hyperthyroidism by rendering the patient hypothyroid [5]. RAI is very effective provided a sufficient radiation dose is delivered in the thyroid. This can be done equally well by a fixed activity of ${ }^{131}$ I or by a calculated activity based on thyroid size and thyroid ${ }^{131}$ I uptake [5]. Balancing rapid relief of hyperthyroidism and postponing hypothyroidism appears to be an elusive goal. No dose calculation can secure long-term euthyroidism [6]. Many centers therefore have given up meticulous dose calculation and use fixed doses of ${ }^{131} \mathrm{I}$ (e.g., 185, 370, or $555 \mathrm{MBq})$.

A recent study evaluating the use of an ablative RAI dose in 576 Graves' patients reports that 1 year after the first fixed ${ }^{131} \mathrm{I}$ dose of $400 \mathrm{MBq}, 17 \%$ was still hyperthyroid, 77\% hypothyroid, and 6\% euthyroid [13]. At 80-month follow-up, 81 patients had received a second dose and eight patients a third dose; 3.2\% was still hyperthyroid (but controlled by ATD or $\mathrm{T}_{\mathrm{x}}$ ), $86.4 \%$ hypothyroid, $3.3 \%$ euthyroid, and $6.4 \%$ had died; no data in $0.7 \%$. Persistent thyrotoxicosis after the first RAI dose was associated with higher free thyroxine (FT4) at diagnosis, higher pre-treatment thyroid stimulating hormone (TSH) receptor antibodies, and post-radioiodine treatment with ATD. New GO after RAI developed in $7.3 \%$. RAI-associated GO is most likely related to a steep increase in TSH receptor antibodies in the first 6 months after RAI, with a slow decrease thereafter: 3 years after RAI, TSI are still positive in $60 \%$ of patients $[10,14]$. Worsening or 
development of GO occurs more often after RAI than after treatment with ATD (38\% vs. 19\%; relative risk, 1.94 ; $95 \%$ confidence interval, 1.4 to 2.7 ) as evident from two randomized clinical trials (RCTs) [15]. Hypothyroidism developed in 95\% after RAI, but euthyroidism was not achieved by any participant [15]. One can conclude that elimination of Graves' hyperthyroidism can be reached by RAI (although often a second or sometimes a third dose of ${ }^{131} \mathrm{I}$ is required), but at the expense of a substantial risk of worsening or developing GO and creating a new disease-hypothyroidism. To replace one disease (hyperthyroidism) by another disease (hypothyroidism) and call that a "cure" of the original disease, seems odd. I would call a disease to be cured if, due to the spontaneous course of the disease or due to specific interventions, after a certain period of time nothing can be found any longer - be it clinical signs and symptoms or biochemical and radiological changes - attributable to that disease. In this context it is interesting to note the definition of remission in Graves' hyperthyroidism. In most studies remission is defined as normal serum TSH, FT4, and triiodothyronine (T3) serum concentrations lasting for 1 year without any treatment. But in a recent Australian study, remission was defined as euthyroidism or hypothyroidism after 12 months, and it was reported that $79 \%$ of patients achieved "remission" with a single dose of ${ }^{131} \mathrm{I}[16]$.

RAI therapy might be considered problematic because of the need for lifelong levothyroxine replacement if the goal is to render the patient hypothyroid. A personalized dosimetric approach delayed the long-term onset of hypothyroidism in $26 \%$ of patients by using much lower administered activities than currently recommended [17]. An interesting RCT in China evaluated the feasibility of ${ }^{131} \mathrm{I}$ therapy aiming at restoration of euthyroidism without the development of hypothyroidism [18]; realization of this goal would come closer to a "cure" of Graves' hyperthyroidism. Eligible patients were randomized into five groups of about 100 patients each. Patients received a range of varying ${ }^{131} \mathrm{I}$ dosages depending on (1) group allocation: 0.37 , $1.11,1.85,2.56$, and $3.33 \mathrm{MBq} / \mathrm{g}$ thyroid tissue was given in group 1, 2, 3, 4, and 5 respectively; (2) clinical score: the score evaluated six items (each scored as 0,1 , or 2) about thyroid gland consistency, duration of disease, previous ATD treatment, severity of disease, complications, and age; the score ranges from 0 to 12 , and $0.37 \mathrm{MBq} / \mathrm{g}$ was added for every 2 scores. Thus e.g., in group 3 the basic activity unit was $1.85 \mathrm{MBq} / \mathrm{g}$ and the therapeutic ${ }^{131} \mathrm{I}$ activity remained $1.85 \mathrm{MBq} / \mathrm{g}$ at clinical score of 0 , but increased to $4.07 \mathrm{MBq} / \mathrm{g}$ at a clinical score of 12 $(1.85 \mathrm{MBq}+6 \times 0.37 \mathrm{MBq})$. In doing so one could compare the effect of various ${ }^{131} \mathrm{I}$ dosages between homogeneous groups as patient characteristics did not differ between the five groups. The optimal outcome (highest proportion of euthyroidism and lowest proportion of hypothyroidism) was obtained in group 3 (average administered activity $261 \pm 162 \mathrm{MBq}$ ): at 12 year, $72 \%$ maintained euthyroidism, $6 \%$ remained hyperthyroid, and $22 \%$ became hypothyroid. Over the 12-year period, the total recurrence rate was $13.6 \%$ [17]. Whether this scheme is preferable to the intentional induction of permanent hypothyroidism recommended by ATA guidelines, remains doubtful.

\section{ANTITHYROID DRUGS}

The third option in the management of Graves' hyperthyroidism is ATDs. ATD have always been the treatment of choice for uncomplicated cases in Europe and Japan, but RAI was the favourite treatment modality in the USA. A 2011 survey reported ATD were preferred by $86 \%$ in Europe and $40 \%$ in North America, whereas RAI was preferred by $13 \%$ in Europe and $59 \%$ in the USA [19]. This has changed dramatically in the USA in the last decade, and now ATD appear the most common treatment in the USA used in 58\% of patients followed by RAI in 35\% [20]. The reason for this shift away from RAI towards ATD might be the realization that RAI is associated with a definite risk for developing or worsening of thyroid eye disease $[14,15]$. Could it be that this shift towards ATD is also related to a greater chance of "cure" of Graves' hyperthyroidism after ATD than after RAI?

\section{Before starting antithyroid drugs}

To know before starting ATD the likelihood of remission after completing a course of ATD, would be very relevant for selecting the most appropriate treatment modality in a particular patient. If the chance of remission is low, $\mathrm{T}_{\mathrm{x}}$ or RAI might be a better option for that patient. Factors associated with a low remission rate as suggested in many but not all studies, are male sex, young age (<40 years), smoking, severe hyperthyroidism, high concentrations of thyrotropin binding inhibitory immunoglobulins (TBIIs), large goiter size, and the presence of GO $[21,22]$. However, the predictive value of each of these risk factors is too low for accurate assessment of the remission chance before starting ATD in the individual patient. A recent prospective study was able to construct a predictive score by combining a number of independent risk factors. This so-called Graves' Recurrent Events After Therapy (GREAT) score provides a reasonable prediction of recurrent Graves' hyperthyroidism after 
Table 1. A Predictive Score (Called the GREAT Score) for the Outcome of Therapy with Antithyroid Drugs in Graves' Hyperthyroidism Based on Four Baseline Characteristics [23]

\begin{tabular}{|c|c|c|}
\hline Marker & GREAT score & Recurrence risk \\
\hline \multicolumn{3}{|l|}{ Age, yr } \\
\hline$\geq 40$ & 0 & \\
\hline$<40$ & 1 & \\
\hline \multicolumn{3}{|l|}{ Serum FT4, pmol/L } \\
\hline$<40$ & 0 & \\
\hline$\geq 40$ & 1 & \\
\hline \multicolumn{3}{|l|}{ Serum TBII, U/L } \\
\hline$<6$ & 0 & \\
\hline $6-19.9$ & 1 & \\
\hline$\geq 20$ & 2 & \\
\hline \multicolumn{3}{|l|}{ Goiter size $^{\mathrm{a}}$} \\
\hline Grade $0-\mathrm{I}$ & 0 & \\
\hline Grade II-III & 2 & \\
\hline \multirow[t]{3}{*}{ Risk stratification } & GREAT score $0-1=$ class I & Recurrences $16 \%$ \\
\hline & GREAT score $2-3=$ class II & Recurrences $44 \%$ \\
\hline & GREAT score 4-6= class III & Recurrences $68 \%$ \\
\hline
\end{tabular}

an 18-months course of ATD [23]. The GREAT score takes into account four baseline characteristics, which are already assessed routinely in the work-up of every patient with Graves' hyperthyroidism: age, FT4, TBII, and goiter size (Table 1) [5,6]. Patients in whom the GREAT score falls in class I, have a rather high chance on remission (84\%), and ATD would be a reasonable option. In contrast, chance on remission is rather low in GREAT score class III (32\%), and $\mathrm{T}_{\mathrm{x}}$ or RAI might be preferred. Chance on remission (56\%) or recurrence (44\%) is about even in patients falling in GREAT score class II; in these patients adding the results of genotyping (human leukocyte antigen subtypes DQB1-02, DQA1-05, DRB1-03, and PTPN22 C/T) generates the $\mathrm{GREAT}^{+}$score which has a greater predictive value and may change management in $38 \%$ of patients [23]. The predictive value of the GREAT score has subsequently been validated by two other independent studies [24,25]. Its accuracy might possibly be enhanced by replacing TBII by an assay which more specifically measures TSH receptor stimulating antibodies $[26,27]$. It is also foreseen that the predictive value of the $\mathrm{GREAT}^{+}$score (which incorporates genotyping) could be enhanced by adding more genotypes related to Graves' disease (like CTLA-4 G/G and TSHR) [28,29].

\section{First course of antithyroid drugs}

A single course of ATD induces remission of Graves' hyperthyroidism in about $50 \%$ of cases $[3,21,30]$. Remission rates vary greatly, however, from $30 \%$ up to $70 \%$ in individual studies. Remission rates are only weakly related to the duration of ATD treatment: 12 to 18 months seems optimal, with slightly higher recurrence rates after 6 months and no apparent additional benefit by extending therapy beyond 18 months [21]. Remission rates do not differ between the titration method (in which the ATD dose is adjusted according to laboratory results) or the block-and-replace method (in which the relatively high ATD starting dose is maintained and levothyroxine is added when euthyroidism has been reached) [31,32]. Excessive iodine intake does not influence remission rates in iodine-replete areas [33]. The mechanisms by which ATD induce a remission, are not completely understood. It might be related to direct effects of ATD on intrathyroidal T-cells [34], but indirect effects on the immune system by restoration of the euthyroid state might play a role as well [35].

Attempts to enhance remission rates so far failed. Administration of levothyroxine after discontinuation of ATD seemed to increase remission rate [36], but subsequent studies could not confirm the initially promising results and this particular treat- 
ment modality is not used any longer [37,38]. Likewise, adding selenium to ATD did increase remission rate in a pilot study [39], but not in a subsequent placebo-controlled RCT [40].

\section{Second course of antithyroid drugs}

It is thought unlikely that patients with recurrent Graves' hyperthyroidism would go into remission after a second course of ATD, and guidelines therefore recommend definitive treatment by RAI or $\mathrm{T}_{\mathrm{x}}$ in case of recurrences. But the last American and European guidelines mention that a second course of ATD might be considered $[5,6]$. In one study from China a second course of ATD lasting for 15 to 20 months resulted in $76 \%$ remissions at a follow-up of 4 years [41]. A Korean study demonstrated similar remission and relapse rates between the first and second course of ATD with 10-year remission rates of 34\% and $25 \%$ respectively, whereas 10 -year remission rates were progressively lower after the third and fourth course of ATD $(17 \%$ and $13 \%$, respectively) [42].

\section{Long-term treatment with antithyroid drugs}

If TBII is negative at the end of 12 to 18 months of ATD therapy, it is reasonable to discontinue ATD as chance on remission is relatively high. Remission chance is relatively low in the presence of high $\mathrm{TSH}$ receptor antibody levels at the end of ATD therapy, a condition sometimes referred to as persistent hyperthyroidism although serum thyroid hormones are normal [6]. It reflects the notion that Graves' hyperthyroidism is not really cured as long as TSH receptor antibodies are present, and I quite agree with this line of thinking. Current guidelines acknowledge the feasibility of continuing ATD for a further 12 months if TBII is still high, or to proceed with long-term use of ATD (usually a low dose of methimazole) $[5,6]$. This strategy has been employed specifically in patients with co-existent GO. In a Dutch study ATD were discontinued after a median treatment duration of 3.5 years (range, 2 to 11): during a median follow-up period of 5 years (range, 1 to 14) recurrent Graves' hyperthyroidism occurred in 37\% (easily managed with ${ }^{131} \mathrm{I}$ ), without a relapse of GO [43]. Long-term treatment with a lowdose of methimazole ( $5 \mathrm{mg} /$ day, $n=101)$ or propylthiouracil (200 mg/day, $n=7$ ) for a median duration of 6.7 years in patients with co-existent severe GO, is reported from Denmark: 90\% maintained euthyroidism during treatment, and the remaining $10 \%$ experienced relapse of hyperthyroidism either spontaneously or after ATD dose reduction [44]. TSH receptor antibodies gradually disappeared from serum in most patients. The only serious side effect of ATD was vasculitis occurring after 6 years of PTU in a 48-year-old woman [44]. A meta-analysis of six studies in which Graves' hyperthyroidism had been treated with ATD for $\geq 2$ years, finds a remission rate of $57 \%$, and a complication rate of $19 \%$ (major complications only in $1.5 \%$ ) [45]. Smoking had a significant lowering effect on remission rate. In a study from Iran patients who had failed to achieve remission on ATD, were randomized into either RAI or further ATD therapy: 10-year outcomes were almost similar with regard to expenses, but hypothyroid episodes were more frequent after RAI than during ATD [46]. A nonrandomized study from Brazil also compared RAI with prolonged low-dose methimazole treatment in patients with recurrent Graves' hyperthyroidism after a course of ATD: RAI was associated with worsening of GO, more weight gain, and more often hypothyroidism at a followup of 5 years [47].

\section{Long-term outcome after initial remission on antithyroid drugs}

The long-term outcome of stable remissions is less well known. We have to rely on studies performed in the 1970s and 1980s, when sensitive TSH assays were not yet available and a single TSH measurement could not discriminate between suppressed and normal TSH values. Consequently the TSH response to TRH was often used. Combining the results of three studies, 170 patients were assembled who were in stable remission for more than 10 years [48-50]. Euthyroidism was observed in $60 \%$, subclinical hyperthyroidism in $16 \%$, subclinical hypothyroidism in $18 \%$, and hypothyroidism in $6 \%$ (Table 2 ).

In one of these studies thyroid histology was available in eight euthyroid patients in longstanding remission: six of them had chronic lymphocytic thyroiditis like in Hashimoto thyroiditis, and none showed diffuse epithelial hyperplasia like in Graves' disease [50]. In the same study, microsomal antibodies (TPO-Ab) had been measured in 22 patients at the time of discontinuation ATD and 10 years later; TPO-Ab were positive in $59 \%$ and $91 \%$ respectively [50]. Another paper investigated 26 patients who developed hypothyroidism 0.5 to 10 years after discontinuation of ATD therapy [51]. Histology showed chronic lymphocytic thyroiditis in eight patients (fibrous variant in three of them) and partial epithelial hyperplasia in one patient. Microsomal antibodies (TPO-Ab) were present in all, TSH blocking antibodies in $33 \%$ and thyroid stimulating antibodies in $66 \%$. TSH blocking antibodies may account for approximately $33 \%$ and chronic lymphocytic thyroiditis for $66 \%$ of these hypothyroid cases [51]. The presence of TPO-Ab is apparently related to the late development of hypothyroidism in Graves' disease, 


\begin{tabular}{|c|c|c|c|c|}
\hline & UK 1977 [48] & USA 1979 [49] & Japan 1986 [50] & Combined [48-50] \\
\hline In remission for & $7.6 \pm 0.6 \mathrm{yr}$ & $20-27 \mathrm{yr}$ & $>10 \mathrm{yr}$ & About $20 \mathrm{yr}$ \\
\hline$\Delta \mathrm{TSH}-\mathrm{TRH} \downarrow$ (subclinical hyperthyroidism) & $17(16)$ & 0 & $10(23)$ & $27(16)$ \\
\hline$\Delta$ TSH-TRH N (euthyroid) & $65(59)$ & $9(60)$ & $28(62)$ & $102(60)$ \\
\hline$\Delta \mathrm{TSH}-\mathrm{TRH} \uparrow$ (subclinical hypothyroidism) & $21(19)$ & $5(33)$ & $5(11)$ & $31(18)$ \\
\hline Hypothyroid & $7(6)$ & $1(7)$ & $2(4)$ & $10(6)$ \\
\hline Total & 110 & 15 & 45 & $170(100)$ \\
\hline
\end{tabular}

Values are expressed as mean $\pm \mathrm{SD}$, range, or number $(\%)$.

$\triangle \mathrm{TSH}-\mathrm{TRH}$, change in serum thyroid stimulating hormone after intravenous administration of TSH releasing hormone; $\mathrm{N}$, normal response.

which comes as no surprise as TPO-Ab is a well-known risk factor for the development of auto-immune hypothyroidism [52]. It is of interest that the presence of TPO-Ab on the other hand seems to protect against recurrent Graves' hyperthyroidism. One hundred and seventeen patients with Graves' hyperthyroidism were treated with ATD for 2 years and then followed for on average 2.5 years; they were divided in group 1 (no thyroglobulin antibody $[\mathrm{Tg}-\mathrm{Ab}]$ and no TPO-Ab), group 2 (no $\mathrm{Tg}$ $\mathrm{Ab}$ but positive TPO-Ab), and group 3 (positive $\mathrm{Tg}-\mathrm{Ab}$ and positive TPO-Ab) before and during ATD therapy. Relapse rates in the three groups were $39 \%, 27 \%$, and $11 \%$ respectively [53]. A more recent study likewise reports that baseline TPO-Ab is inversely associated with relapse rates in a dose-dependent manner [54]. The data suggest patients with TPO-Ab are least likely to relapse, but more likely to proceed to hypothyroidism. However, other studies did not find TPO-Ab measurements useful for prediction of remissions or recurrences $[55,56]$.

The perplexing conclusion of very long-term follow-up studies in Graves' patients in stable remission is that $40 \%$ have still abnormal thyroid function, related to the persistence of thyroid antibodies (Table 2). In 16\% there exists subclinical hyperthyroidism, most likely due to the persistence of TSH receptor stimulating antibodies. In $24 \%$ there exists subclinical or overt hypothyroidism, related to either TSH receptor blocking antibodies or TPO-Abs. Interestingly, many patients in this group also have persistent TSH receptor stimulating antibodies. It illustrates again how the interplay between destructive/inhibitory and stimulatory immunological effector mechanisms determines the outcome of thyroid function in autoimmune diseases [57]. The co-existence of TSH receptor stimulating and blocking antibodies is of particular pathophysiological interest. Remissions of Graves' hyperthyroidism are caused by a decrease of TSH re- ceptor stimulating antibodies, but can an increase in TSH receptor blocking antibodies contribute to remissions? Alternating hyperthyroidism and hypothyroidism in Graves' disease has indeed been linked to switches between TSH receptor stimulating and blocking antibodies [58]. Can hypothyroidism induced by TSH receptor blocking antibodies still be called Graves' disease? Have hypothyroid patients with both TSH receptor blocking antibodies and TPO-Abs two simultaneous diseases, Graves' disease and Hashimoto thyroiditis? Or do they belong to one and the same disease entity, namely autoimmune thyroid disease? Apart from these semantical issues, it is clear that Graves' hyperthyroidism cannot be called really cured in the presence of still abnormal thyroid function.

\section{CONCLUSIONS}

Whether or not Graves' hyperthyroidism can be cured, depends on the definition of 'cure.' If cure is defined as just disappearance of thyroid hormone excess, then cure is possible in almost all cases by either $T_{x}$, RAI, or ATD. Cure defined as 'restitutio ad integrum' implies maintenance of the euthyroid state like it was before the illness, that is without any medication and without thyroid antibodies in the circulation. Guidelines state the aim of $T_{x}$ or RAI in Graves' hyperthyroidism should be permanent hypothyroidism, which requires lifelong levothyroxine medication for maintaining euthyroidism. Creating another disease in order to treat the original disease, is no cure. ATDs leave open the possibility of cure, defined as maintenance of the euthyroid state (normal TSH, FT4, and T3) without the use of any medication.

The average remission rate after a course of ATD is about $50 \%$ [21]. Most recurrences occur within 4 years after discon- 


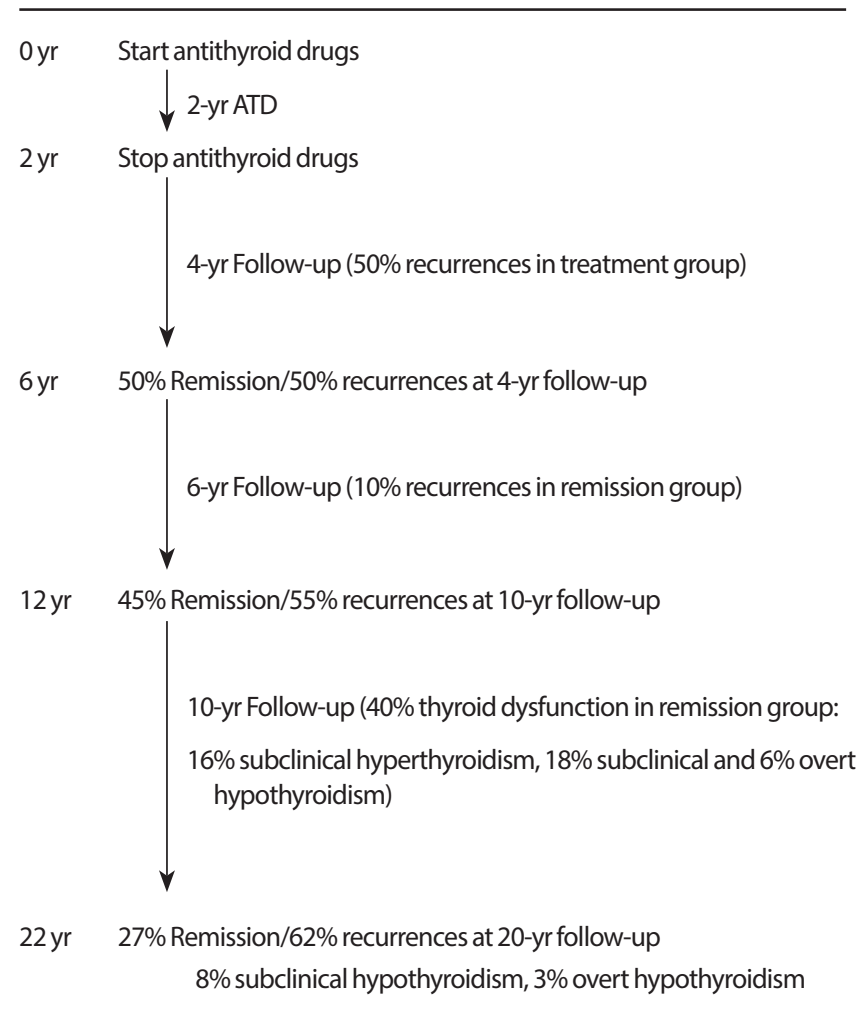

Fig. 2. Chance of remission of Graves' hyperthyroidism after a course of antithyroid drugs. ATD, antithyroid drug.

tinuation of ATD [3]. Although prognosis is excellent after 4 years without relapse [30], late recurrences do occur and only one in three patients experiences permanent remission [21]. Remission rate after 10 years is in the order of $30 \%$ to $40 \%$, and hypothyroidism has developed in $10 \%$ to $15 \% 15$ years after ATD [59]. Taken into account the above reviewed literature, permanent cure of Graves' hyperthyroidism is possible albeit at a low rate of about $27 \%$ (Fig. 2). The cure rate would be even lower if cure also supposes the absence of TSH receptor antibodies.

\section{CONFLICTS OF INTEREST}

No potential conflict of interest relevant to this article was reported.

\section{REFERENCES}

1. Smith TJ, Hegedus L. Graves' disease. N Engl J Med 2016; 375:1552-65.

2. Nystrom HF, Jansson S, Berg G. Incidence rate and clinical features of hyperthyroidism in a long-term iodine sufficient area of Sweden (Gothenburg) 2003-2005. Clin Endocrinol (Oxf) 2013;78:768-76.

3. Hussain YS, Hookham JC, Allahabadia A, Balasubramanian SP. Epidemiology, management and outcomes of Graves' disease-real life data. Endocrine 2017;56:568-78.

4. Wass JAH, Stewart PM. Oxford textbook of endocrinology and diabetes. 2nd ed. Oxford: Oxford University Press; 2011. Chapter 3.3.6, Antithyroid drug treatment for thyrotoxicosis; p. 476-80.

5. Ross DS, Burch HB, Cooper DS, Greenlee MC, Laurberg P, Maia AL, et al. 2016 American Thyroid Association guidelines for diagnosis and management of hyperthyroidism and other causes of thyrotoxicosis. Thyroid 2016;26:1343-421.

6. Kahaly GJ, Bartalena L, Hegedus L, Leenhardt L, Poppe K, Pearce SH. 2018 European Thyroid Association guideline for the management of Graves' hyperthyroidism. Eur Thyroid J 2018;7:167-86.

7. Guo Z, Yu P, Liu Z, Si Y, Jin M. Total thyroidectomy vs bilateral subtotal thyroidectomy in patients with Graves' diseases: a meta-analysis of randomized clinical trials. Clin Endocrinol (Oxf) 2013;79:739-46.

8. Genovese BM, Noureldine SI, Gleeson EM, Tufano RP, Kandil E. What is the best definitive treatment for Graves' disease? A systematic review of the existing literature. Ann Surg Oncol 2013;20:660-7.

9. Liu ZW, Masterson L, Fish B, Jani P, Chatterjee K. Thyroid surgery for Graves' disease and Graves' ophthalmopathy. Cochrane Database Syst Rev 2015;11:CD010576.

10. Kautbally S, Alexopoulou O, Daumerie C, Jamar F, Mourad M, Maiter D. Greater efficacy of total thyroidectomy versus radioiodine therapy on hyperthyroidism and thyroid-stimulating immunoglobulin levels in patients with Graves' disease previously treated with antithyroid drugs. Eur Thyroid J 2012;1:122-8.

11. Lin YS, Lin JD, Hsu CC, Yu MC. The long-term outcomes of thyroid function after subtotal thyroidectomy for Graves' hyperthyroidism. J Surg Res 2017;220:112-8.

12. Huang CS, Wang M, Shun CT, Liaw KY. Factors affecting thyroid function after thyroidectomy for Graves' disease. J Formos Med Assoc 1995;94:423-7.

13. Aung ET, Zammitt NN, Dover AR, Strachan MWJ, Seckl JR, Gibb FW. Predicting outcomes and complications following radioiodine therapy in Graves' thyrotoxicosis. Clin Endocrinol (Oxf) 2019;90:192-9.

14. Laurberg P, Wallin G, Tallstedt L, Abraham-Nordling M, 
Lundell G, Torring O. TSH-receptor autoimmunity in Graves' disease after therapy with anti-thyroid drugs, surgery, or radioiodine: a 5-year prospective randomized study. Eur J Endocrinol 2008;158:69-75.

15. Ma C, Xie J, Wang H, Li J, Chen S. Radioiodine therapy versus antithyroid medications for Graves' disease. Cochrane Database Syst Rev 2016;2:CD010094.

16. Fanning E, Inder WJ, Mackenzie E. Radioiodine treatment for Graves' disease: a 10-year Australian cohort study. BMC Endocr Disord 2018;18:94.

17. Hyer SL, Pratt B, Gray M, Chittenden S, Du Y, Harmer CL, et al. Dosimetry-based treatment for Graves' disease. Nucl Med Commun 2018;39:486-92.

18. Chen DY, Schneider PF, Zhang XS, He ZM, Jing J, Chen TH. Striving for euthyroidism in radioiodine therapy of Graves' disease: a 12-year prospective, randomized, openlabel blinded end point study. Thyroid 2011;21:647-54.

19. Burch HB, Burman KD, Cooper DS. A 2011 survey of clinical practice patterns in the management of Graves' disease. J Clin Endocrinol Metab 2012;97:4549-58.

20. Brito JP, Schilz S, Singh Ospina N, Rodriguez-Gutierrez R, Maraka S, Sangaralingham LR, et al. Antithyroid drugs-the most common treatment for Graves' disease in the United States: a nationwide population-based study. Thyroid 2016; 26:1144-5.

21. Burch HB, Cooper DS. Anniversary review: antithyroid drug therapy: 70 years later. Eur J Endocrinol 2018;179: R261-74.

22. Struja T, Fehlberg H, Kutz A, Guebelin L, Degen C, Mueller B, et al. Can we predict relapse in Graves' disease? Results from a systematic review and meta-analysis. Eur J Endocrinol 2017;176:87-97.

23. Vos XG, Endert E, Zwinderman AH, Tijssen JG, Wiersinga WM. Predicting the risk of recurrence before the start of antithyroid drug therapy in patients with Graves' hyperthyroidism. J Clin Endocrinol Metab 2016;101:1381-9.

24. Struja T, Kaeslin M, Boesiger F, Jutzi R, Imahorn N, Kutz A, et al. External validation of the GREAT score to predict relapse risk in Graves' disease: results from a multicenter, retrospective study with 741 patients. Eur J Endocrinol 2017; 176:413-9.

25. Masiello E, Veronesi G, Gallo D, Premoli P, Bianconi E, Rosetti S, et al. Antithyroid drug treatment for Graves' disease: baseline predictive models of relapse after treatment for a patient-tailored management. J Endocrinol Invest 2018;41: 1425-32.
26. Giuliani C, Cerrone D, Harii N, Thornton M, Kohn LD, Dagia NM, et al. A TSHR-LH/CGR chimera that measures functional thyroid-stimulating autoantibodies (TSAb) can predict remission or recurrence in Graves' patients undergoing antithyroid drug (ATD) treatment. J Clin Endocrinol Metab 2012;97:E1080-7.

27. Kwon H, Kim WG, Jang EK, Kim M, Park S, Jeon MJ, et al. Usefulness of measuring thyroid stimulating antibody at the time of antithyroid drug withdrawal for predicting relapse of Graves disease. Endocrinol Metab (Seoul) 2016;31:300-10.

28. Eliana F, Suwondo P, Asmarinah A, Harahap A, Djauzi S, Prihartono J, et al. The role of cytotoxic T-lymphocyte-associated protein 4 (CTLA-4) gene, thyroid stimulating hormone receptor (TSHR) gene and regulatory t-cells as risk factors for relapse in patients with Graves disease. Acta Med Indones 2017;49:195-204.

29. Garcia-Mayor RV, Alvarez-Vazquez P, Fluiters E, Valverde D, Andrade A. Long-term remission following antithyroid drug withdrawal in patients with Graves' hyperthyroidism: parameters with prognostic value. Endocrine 2019;63:31622.

30. Mohlin E, Filipsson Nystrom H, Eliasson M. Long-term prognosis after medical treatment of Graves' disease in a northern Swedish population 2000-2010. Eur J Endocrinol 2014;170:419-27.

31. Abraham P, Avenell A, Park CM, Watson WA, Bevan JS. A systematic review of drug therapy for Graves' hyperthyroidism. Eur J Endocrinol 2005;153:489-98.

32. Razvi S, Vaidya B, Perros P, Pearce SH. What is the evidence behind the evidence-base? The premature death of block-replace antithyroid drug regimens for Graves' disease. Eur J Endocrinol 2006;154:783-6.

33. Park SM, Cho YY, Joung JY, Sohn SY, Kim SW, Chung JH. Excessive iodine intake does not increase the recurrence rate of Graves' disease after withdrawal of the antithyroid drug in an iodine-replete area. Eur Thyroid J 2015;4:36-42.

34. Volpe R. The immunomodulatory effects of anti-thyroid drugs are mediated via actions on thyroid cells, affecting thyrocyte-immunocyte signalling: a review. Curr Pharm Des 2001;7:451-60.

35. Laurberg P. Remission of Graves' disease during anti-thyroid drug therapy. Time to reconsider the mechanism? Eur J Endocrinol 2006;155:783-6.

36. Hashizume K, Ichikawa K, Sakurai A, Suzuki S, Takeda T, Kobayashi M, et al. Administration of thyroxine in treated Graves' disease. Effects on the level of antibodies to thyroid-

Copyright (C) 2019 Korean Endocrine Society 
stimulating hormone receptors and on the risk of recurrence of hyperthyroidism. N Engl J Med 1991;324:947-53.

37. Tamai H, Hayaki I, Kawai K, Komaki G, Matsubayashi S, Kuma K, et al. Lack of effect of thyroxine administration on elevated thyroid stimulating hormone receptor antibody levels in treated Graves' disease patients. J Clin Endocrinol Metab 1995;80:1481-4.

38. Mori T, Sugawa H, Kosugi S, Ueda M, Hai N, Matsuda A. Recent trends in the management of Graves' hyperthyroidism in Japan: opinion survey results, especially on the combination therapy of antithyroid drug and thyroid hormone. Endocr J 1997;44:509-17.

39. Wang L, Wang B, Chen SR, Hou X, Wang XF, Zhao SH, et al. Effect of selenium supplementation on recurrent hyperthyroidism caused by Graves' disease: a prospective pilot study. Horm Metab Res 2016;48:559-64.

40. Kahaly GJ, Riedl M, Konig J, Diana T, Schomburg L. Double-blind, placebo-controlled, randomized trial of selenium in Graves hyperthyroidism. J Clin Endocrinol Metab 2017; 102:4333-41.

41. Liu X, Qiang W, Liu X, Liu L, Liu S, Gao A, et al. A second course of antithyroid drug therapy for recurrent Graves' disease: an experience in endocrine practice. Eur J Endocrinol 2015;172:321-6.

42. Kim YA, Cho SW, Choi HS, Moon S, Moon JH, Kim KW, et al. The second antithyroid drug treatment is effective in relapsed Graves' disease patients: a median 11-year followup study. Thyroid 2017;27:491-6.

43. Elbers L, Mourits M, Wiersinga W. Outcome of very longterm treatment with antithyroid drugs in Graves' hyperthyroidism associated with Graves' orbitopathy. Thyroid 2011; 21:279-83.

44. Laurberg P, Berman DC, Andersen S, Bulow Pedersen I. Sustained control of Graves' hyperthyroidism during longterm low-dose antithyroid drug therapy of patients with severe Graves’ orbitopathy. Thyroid 2011;21:951-6.

45. Azizi F, Malboosbaf R. Long-term antithyroid drug treatment: a systematic review and meta-analysis. Thyroid 2017; 27:1223-31.

46. Azizi F, Ataie L, Hedayati M, Mehrabi Y, Sheikholeslami F. Effect of long-term continuous methimazole treatment of hyperthyroidism: comparison with radioiodine. Eur J Endocrinol 2005; 152:695-701.

47. Villagelin D, Romaldini JH, Santos RB, Milkos AB, Ward LS. Outcomes in relapsed Graves' disease patients following radioiodine or prolonged low dose of methimazole treat- ment. Thyroid 2015;25:1282-90.

48. Irvine WJ, Gray RS, Toft AD, Seth J, Lidgard GP, Cameron EH. Spectrum of thyroid function in patient's remaining in remission after antithyroid drug therapy for thyrotoxicosis. Lancet 1977;2:179-81.

49. Wood LC, Ingbar SH. Hypothyroidism as a late sequela in patient with Graves' disease treated with antithyroid agents. J Clin Invest 1979;64:1429-36.

50. Hirota Y, Tamai H, Hayashi Y, Matsubayashi S, Matsuzuka F, Kuma K, et al. Thyroid function and histology in fortyfive patients with hyperthyroid Graves' disease in clinical remission more than ten years after thionamide drug treatment. J Clin Endocrinol Metab 1986;62:165-9.

51. Tamai H, Kasagi K, Takaichi Y, Takamatsu J, Komaki G, Matsubayashi S, et al. Development of spontaneous hypothyroidism in patients with Graves' disease treated with antithyroidal drugs: clinical, immunological, and histological findings in 26 patients. J Clin Endocrinol Metab 1989;69: 49-53.

52. Strieder TG, Tijssen JG, Wenzel BE, Endert E, Wiersinga WM. Prediction of progression to overt hypothyroidism or hyperthyroidism in female relatives of patients with autoimmune thyroid disease using the Thyroid Events Amsterdam (THEA) score. Arch Intern Med 2008;168:1657-63.

53. Takaichi Y, Tamai H, Honda K, Nagai K, Kuma K, Nakagawa $T$. The significance of antithyroglobulin and antithyroidal microsomal antibodies in patients with hyperthyroidism due to Graves' disease treated with antithyroidal drugs. J Clin Endocrinol Metab 1989;68:1097-100.

54. Stefanic M, Karner I. Thyroid peroxidase autoantibodies are associated with a lesser likelihood of late reversion to hyperthyroidism after successful non-ablative treatment of Graves' disease in Croatian patients. J Endocrinol Invest 2014;37:717.

55. Lin HD, Tai FT, Chen HD, Lee SP, Chang FY, Wang GG, et al. Change of circulating thyroid autoantibody titers in Graves' hyperthyroidism after antithyroid drugs therapy. Zhonghua Yi Xue Za Zhi (Taipei) 1991;47:86-90.

56. Schott M, Eckstein A, Willenberg HS, Nguyen TB, Morgenthaler NG, Scherbaum WA. Improved prediction of relapse of Graves' thyrotoxicosis by combined determination of TSH receptor and thyroperoxidase antibodies. Horm Metab Res 2007;39:56-61.

57. Gill RG, Harmon JT, McLaren NK. Immunologically mediated endocrine diseases. Philadelphia: Lippincott Williams \& Wilkins; 2002. Chapter 18, Autoimmune thyroid diseases; 
p. 373-96.

58. Wong M, Inder WJ. Alternating hyperthyroidism and hypothyroidism in Graves' disease. Clin Case Rep 2018;6:1684-8.
59. Weetman AP. Graves' disease. N Engl J Med 2000;343:123648. 